\title{
Sleep Habits of Elementary and Middle School Children in South Texas
}

\author{
Salim Surani, ${ }^{1,2}$ Sean Hesselbacher, ${ }^{3,4}$ Saherish Surani, ${ }^{2}$ Sreevidya Sadasiva, ${ }^{2}$ \\ Zoya Surani, ${ }^{2}$ Sara S. Surani, ${ }^{5}$ Amina Khimani, ${ }^{6}$ and Shyam Subramanian ${ }^{7}$ \\ ${ }^{1}$ Texas A\&M University, Corpus Christi, TX 78405, USA \\ ${ }^{2}$ Pulmonary Associates, Corpus Christi, TX 78336, USA \\ ${ }^{3}$ Sentara Healthcare, Virginia Beach, VA 23454, USA \\ ${ }^{4}$ Eastern Virginia Medical School, Norfolk, VA 23507, USA \\ ${ }^{5}$ Harvard University, Boston, MA 02138, USA \\ ${ }^{6}$ University of California, Berkeley, CA 94720, USA \\ ${ }^{7}$ Mercy Health, Cincinnati, OH 45202, USA
}

Correspondence should be addressed to Salim Surani; srsurani@hotmail.com

Received 23 August 2015; Revised 16 November 2015; Accepted 17 November 2015

Academic Editor: Marco Zucconi

Copyright (C) 2015 Salim Surani et al. This is an open access article distributed under the Creative Commons Attribution License, which permits unrestricted use, distribution, and reproduction in any medium, provided the original work is properly cited.

Background. Sleep difficulties, including insufficient sleep and inadequate sleep hygiene, have been prevalent among children. Sleep deprivation can lead to poor grades, sleepiness, and moodiness. We undertook this study to assess the prevalence of sleep abnormalities among elementary and middle school students in South Texas and how the groups compare with one another. Method. After approval from the appropriate school district for a sleep education program, a baseline survey was taken of elementary and middle school students, using the Children's Sleep Habit Questionnaire-Sleep Self-Report Form, which assessed the domains of bedtime resistance, sleep onset delay, sleep anxiety, sleep duration, night awakening, and daytime sleepiness. Results. The survey was completed by 499 elementary and 1008 middle school children. Trouble sleeping was reported by $43 \%$ in elementary school, compared with $29 \%$ of middle school children. Fifty percent of middle school children did not like sleeping, compared with $26 \%$ in elementary school. Bedtime resistance, sleep onset delay, and nighttime awakening were more common among elementary school students. Daytime sleepiness was more common among the middle school children when compared to elementary school children. Conclusions. Sleep abnormalities are present in elementary school children with changes in sleep habits into middle school.

\section{Introduction}

Insufficient sleep syndrome "occurs when an individual persistently fails to obtain the amount of sleep required to maintain normal levels of alertness and wakefulness. The individual is chronically sleep deprived as a result of failure to achieve necessary sleep time due to reduced time in bed." Inadequate sleep hygiene is characterized by sleep and wake difficulties resulting from "daily living activities that are inconsistent with the maintenance of good-quality sleep and normal daytime alertness" [1]. These problems are common among adolescents and children [2-7].
The Centers for Disease Control currently recommend 910 hours of sleep nightly in teenagers and $10+$ hours in school age children [8]; the National Sleep Foundation Scientific Advisory Council similarly recommends 9-11 hours for school age children and 8-10 hours for teenagers [9]. Only $15 \%$ of teens slept 8.5 hours or more on school nights [10] and $70 \%$ have a bedtime of $10 \mathrm{PM}$ or later. Common reasons given for delayed sleep included homework, hanging out with friends, television, stress, and part-time jobs [5]. A recently published yearly cross-sectional survey of adolescents revealed that the percentage of teens achieving $\geq 7$ hours of sleep nightly decreases each year from ages 12 through 18 
and has shown an overall decline over the past 20 years [7]. Teens are more inclined to have irregular sleep patterns across the week and tend to stay up late and sleep in late on weekends [10]. Irregular sleep patterns are detrimental to the biological clock and affect sleep quality. Sleep deprivation can adversely affect academics, behaviors, and overall health $[3,4,6,11,12]$.

Approximately, $90 \%$ of parents feel that their children are getting adequate sleep. Conversely, $60 \%$ of the adolescents reported difficulty getting out of bed in the morning and majority of them required their parents to wake them up for school [11, 13, 14]. These conflicting reports highlight discrepancies in the ways parents and children view the adequacy of the children's sleep.

We undertook this study to assess the prevalence of sleeprelated problems among school children in South Texas, including inadequate sleep hygiene and insufficient sleep, and to ascertain some of the differences in sleep habits between children of elementary and middle school ages. The majority of the sleep related studies that have been conducted in United States of America and Europe have been on Caucasian population. Very little research has been done among US Hispanic population. Based on the demographic and prevalent risk factors as diabetes, obesity, low socioeconomic factors, high incidence of obstructive sleep apnea, and low educational status points toward sleep habit [15]. This is the first attempt to get the epidemiological information as it relates to sleep among children in South Texas. 65\% of the population in the region is of Hispanic ethnicity, with low percentage of professionals, and only $21 \%$ of them are college graduates. There are 38,938 students enrolled in this school district; of those $78.9 \%$ are of Hispanic ethnicity [16]. Enrollment in the middle schools is larger than that of the elementary schools as several feeder elementary schools feed into one middle school; therefore, data were collected from 1 middle school and 2 elementary schools. We attempted to approximate the overall population demographics in the groups chosen to answer the questionnaires: the ethnic composition of the middle school is similar to that of the school district as a whole. Elementary school \#1 has a higher Hispanic population, lower proportion of Caucasians, and lower socioeconomic status than the composition of the school district; the inverse is true of elementary school \#2. We aimed to compare these groups based on self-reported sleep habits, which can often be different from the perception of the parents.

\section{Methods}

Participants were elementary (4th and 5 th grades) and middle (6th through 8th grades) school students taking part in a school-sponsored sleep education program. Permission was obtained from the Corpus Christi Independent School District prior to embarking on the broader sleep education program. All elementary and middle schools in the school district were offered participation in the sleep education program; 2 elementary and 1 middle schools were chosen to participate in the first wave of education, with the baseline data reported here being collected from these schools. The schools were felt, by consensus of the investigators, to represent the overall school district as closely as possible. All participants completed the Children's Sleep Habits Questionnaire-Sleep Self Report Form (CSHQ-SSRF). The CSHQ is a validated tool, assessing students in the domains of bedtime resistance, sleep onset delay, sleep anxiety, sleep duration, night awakening, and daytime sleepiness, which has demonstrated good internal consistency in both community and clinical samples [17]. The CSHQ-SSRH is a 26 -item survey, which is designed to assess sleep domains similar to the CSHQ, completed by the student (rather than parent or caregiver) $[18,19]$. The items are grouped into six blocks, with each addressing an aspect of sleep quality/quantity, and are answered based on a 3-point scale. The points system designates "usually" (5-7 times/week), "sometimes" (2-4 times/week), and "rarely" (0-1 times/week); a higher score indicates more abnormal sleep [20]. The sum of the scores for the whole questionnaire (questions 2 through 26) has a possible maximum score of 73 and a minimum score of 23. All completed questionnaires were accepted for analysis; incomplete questionnaires were excluded.

2.1. Statistics. Statistical analysis was performed using $\mathrm{R}$ Statistical Software (Foundation for Statistical Computing, Vienna, Austria). The proportion of responses to the questionnaire was calculated to determine baseline sleep habits and problems. The mean scores were calculated for each question and the overall questionnaire. $t$-test was performed on the mean scores of each group of questions (except group 2 which is a single question) to detect the differences between the groups. As shown in Figure 1, the distribution of total questionnaire scores for each group of students was normally distributed; the same was assumed to hold true for groups of multiple questions. Because the responses to single questions were categorical data, the proportion of responses to each question was compared between the groups using contingency tables. A $P$ value of $<0.05$ was considered statistically significant.

\section{Results}

3.1. Demographic Characteristics. A total of 499 elementary school students (360 4th grade, 139 5th grade) submitted questionnaires, of which 387 were complete; 1000 of 1008 middle school surveys submitted were complete. Demographic data of the individual respondents are unavailable. The demographic characteristics of the students in each school in the most recent year for which data are available (2010) are represented in Table 1. All schools had a predominance of Hispanic ethnicity. The ethnic make-up of elementary school \#2 (ES2) was significantly different than that of elementary school \#1 (ES1, $P<0.0001$ ) and the middle school (MS, $P<0.0001$ ), which were similar to each other. The population of ES2 was comprised of fewer Hispanics and African Americans and more Caucasians and Asians/Pacific Islanders than the other 2 schools. A significantly higher proportion of students in ES1 were economically disadvantaged than in MS, which had a higher proportion than ES2; similar findings were identified for at-risk children. Both elementary schools had significantly more students with limited English 
TABLE 1: Demographic characteristics of the students.

\begin{tabular}{|c|c|c|c|}
\hline School & Elementary \#1 & Elementary \#2 & Middle \\
\hline \multicolumn{4}{|l|}{ Ethnicity } \\
\hline Hispanic & $68.5 \%$ & $47.4 \%$ & $67.3 \%$ \\
\hline Caucasian & $24.4 \%$ & $39.8 \%$ & $23.6 \%$ \\
\hline African American & $5.8 \%$ & $2 \%$ & $6 \%$ \\
\hline Asian/Pacific Islander & $1.3 \%$ & $10.1 \%$ & $2.9 \%$ \\
\hline Native American & $0 \%$ & $0.6 \%$ & $0.2 \%$ \\
\hline \multicolumn{4}{|l|}{ Risk factors } \\
\hline Economically disadvantaged & $58.7 \%$ & $29.4 \%$ & $36.8 \%$ \\
\hline At risk & $42.3 \%$ & $18.3 \%$ & $30 \%$ \\
\hline Limited English proficient & $1.9 \%$ & $3.8 \%$ & $0.1 \%$ \\
\hline Teacher experience (mean years) & 16.8 & 17.6 & 15.8 \\
\hline
\end{tabular}

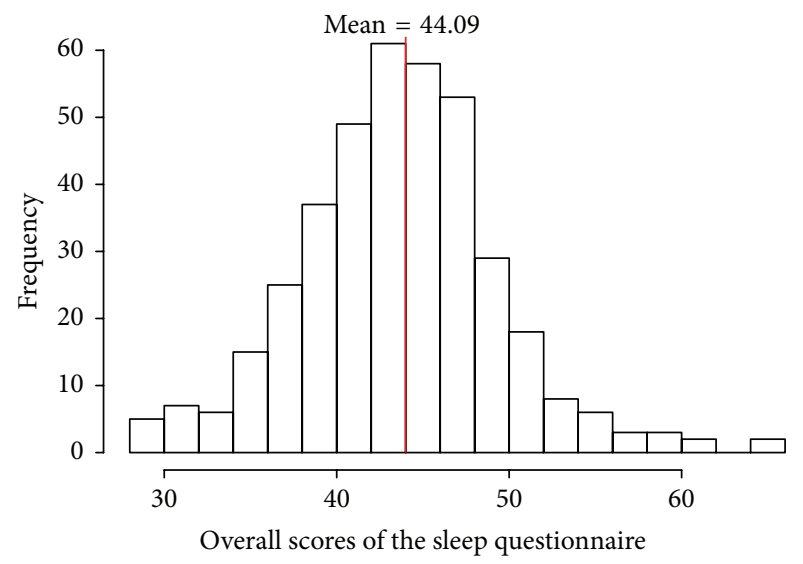

(a)

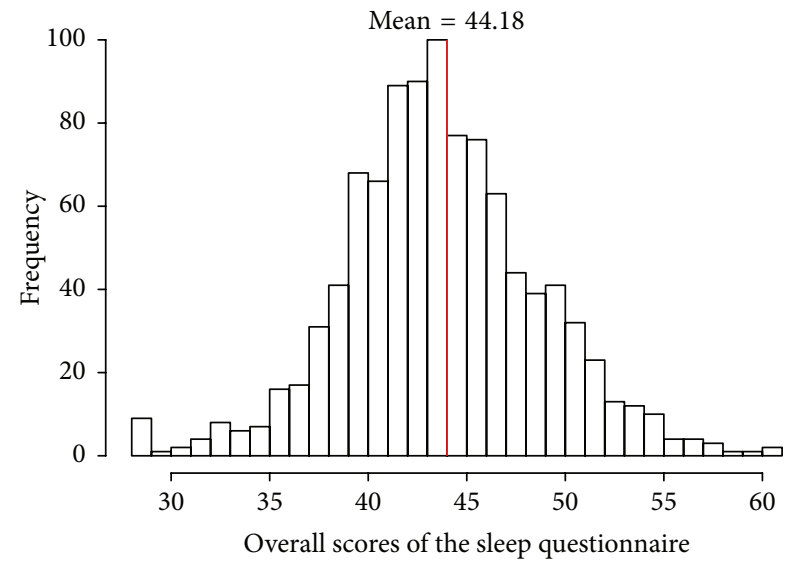

(b)

FIGURE 1: Distribution of the total questionnaire scores for elementary (a) and middle (b) school students.

proficiency than the MS, though they were similar to each other in this respect.

3.2. Sleep Habits of Elementary School Students. The questionnaire total scores ranged from 28 to 65 (of a possible 73), with a mean of 44 as can be seen in Figure 1(a). Responses to the individual questions are listed in Table 2 . Of the 387 students that completed the questionnaire, $43 \%$ had trouble sleeping and 26\% did not like to sleep. Major sleep issues were seen in different blocks of the questionnaire in $10 \%-40 \%$ of students: $44 \%$ of the students rarely slept in the same bed; $31 \%$ usually stayed up late when parents thought they were asleep; only $28 \%$ of students fell asleep within 20 minutes; $34 \%$ rarely felt rested after a good night's sleep.

3.3. Sleep Habits of Middle School Students. Among the middle school students, the total questionnaire scores ranged from 28 to 61 with mean of 44 which is graphically depicted in Figure 1(b). The breakdown of the responses to each question is detailed in Table 3: $29 \%$ had trouble sleeping and 50\% did not like to sleep; $10 \%-50 \%$ of students had major sleep issues in different blocks of the questionnaire; $50 \%$ of the students rarely sleep alone; $50 \%$ are rarely ready to go to bed at usual bedtime; approximately one-third of students usually find it difficult to go to bed; $40 \%$ take naps during day time; only $22 \%$ of students fell asleep within 20 minutes; $40 \%$ felt rested after a good night's sleep.

3.4. Comparison of Elementary and Middle School Data. A question-by-question comparison between elementary and middle school students is detailed in Table 4. There was a significant difference in the percent of students who had trouble sleeping and $43 \%$ in elementary compared to $29 \%$ in middle school $(P<0.01)$. Also, the percentage of students who did not like sleeping was different between the groups, $26 \%$ in elementary and $50 \%$ in middle school $(P<0.01)$. The two groups differed significantly on 20 of the 25 questions by Chi square analysis.

Responses to the Bedtime Resistance block of questions differed significantly between the 2 groups $(P=0.01)$. Middle school students were more likely to go to bed at the same time $(P<0.01)$ on school nights, in the same bed $(P<0.01)$, and were less likely to stay up late when the parents thought they were asleep $(P<0.01)$. In the same block of questions, 
TABLE 2: Responses to the Children's Sleep Habits Questionnaire from elementary school students.

\begin{tabular}{|c|c|c|c|c|}
\hline Qn \# & & Yes & No & \\
\hline 2 & Trouble sleeping & $43.04 \%$ & $56.96 \%$ & \\
\hline \multirow[t]{2}{*}{3} & Likes to sleep & $73.55 \%$ & $26.45 \%$ & \\
\hline & & Rarely & Sometimes & Usually \\
\hline \multicolumn{5}{|c|}{ Block 1: bedtime resistance } \\
\hline 4 & Goes to bed at same time & $30.16 \%$ & $36.64 \%$ & $33.20 \%$ \\
\hline 5 & Falls asleep in same bed & $32.25 \%$ & $27.99 \%$ & $39.76 \%$ \\
\hline 6 & Sleeps alone & $37.96 \%$ & $24.69 \%$ & $37.35 \%$ \\
\hline 7 & Falls asleep in other's bed & $46.41 \%$ & $30.80 \%$ & $22.79 \%$ \\
\hline 9 & Fights with parents to go to bed & $61.20 \%$ & $25.93 \%$ & $12.86 \%$ \\
\hline 10 & Hard to go to bed & $41.36 \%$ & $33.33 \%$ & $25.31 \%$ \\
\hline 11 & Ready to sleep at usual bedtime & $43.67 \%$ & $30.00 \%$ & $26.33 \%$ \\
\hline 15 & Stay up late when parents think you are asleep & $39.51 \%$ & $28.72 \%$ & $31.77 \%$ \\
\hline \multicolumn{5}{|c|}{ Block 2: sleep onset delay } \\
\hline 8 & Falls asleep in 20 minutes & $36.21 \%$ & $36.01 \%$ & $27.78 \%$ \\
\hline \multicolumn{5}{|c|}{ Block 3: sleep anxiety } \\
\hline 12 & Takes a special thing to bed & $48.05 \%$ & $25.05 \%$ & $26.90 \%$ \\
\hline 13 & Afraid of dark & $60.33 \%$ & $20.45 \%$ & $19.22 \%$ \\
\hline 14 & Afraid of sleeping alone & $58.80 \%$ & $25.47 \%$ & $15.73 \%$ \\
\hline \multicolumn{5}{|c|}{ Block 4: sleep duration } \\
\hline 16 & Sleeps too little & $48.98 \%$ & $28.69 \%$ & $22.34 \%$ \\
\hline 17 & Sleeps too much & $55.56 \%$ & $28.19 \%$ & $16.26 \%$ \\
\hline \multicolumn{5}{|c|}{ Block 5: night awakening } \\
\hline 18 & Wakes up at night when parents think you are asleep & $47.20 \%$ & $30.23 \%$ & $22.57 \%$ \\
\hline 19 & Trouble falling back asleep after waking up & $45.74 \%$ & $28.90 \%$ & $25.36 \%$ \\
\hline 20 & Have nightmares & $48.35 \%$ & $33.13 \%$ & $18.52 \%$ \\
\hline 21 & Wakes up due to pain & $57.02 \%$ & $27.04 \%$ & $15.93 \%$ \\
\hline 22 & Goes to other's bed during night & $60.96 \%$ & $28.39 \%$ & $10.65 \%$ \\
\hline \multicolumn{5}{|c|}{ Block 6: daytime sleepiness } \\
\hline 23 & Trouble waking up in morning & $37.22 \%$ & $35.17 \%$ & $27.61 \%$ \\
\hline 24 & Feels sleepy during day & $41.31 \%$ & $40.29 \%$ & $18.40 \%$ \\
\hline 25 & Takes naps during day & $56.03 \%$ & $28.63 \%$ & $15.34 \%$ \\
\hline 26 & Feels rested after a night's sleep & $33.61 \%$ & $30.53 \%$ & $35.86 \%$ \\
\hline
\end{tabular}

Qn \#: question number.

elementary students answered that they fought over going to bed less frequently $(P<0.01)$ and were more often ready to go to bed at the usual bedtime $(P=0.01)$. Only $22 \%$ of middle school students reported falling asleep within 20 minutes, compared with $36 \%$ of elementary school students $(P<$ 0.01). The Sleep Anxiety block of questions did not differ overall. Elementary students more often reported taking a special thing to bed $(P<0.01)$ and being afraid of the dark $(P<0.01)$ but were less often afraid of sleeping alone $(P<0.01)$. More elementary students answered that they sleep too little $(P<0.01)$ and too much $(P<0.01)$, though the overall Sleep Duration block did not demonstrate a significant difference. The Night Awakening block of questions was not different between the groups. More elementary students reported nightmares $(P<0.01)$ and having trouble falling back asleep after awakening $(P<0.01)$, though middle school students more often go to someone else's bed during the night
$(P<0.01)$. Middle schools students were more sleepy than elementary students overall $(P<0.01)$, more often reporting feeling sleepy during the day $(P<0.01)$, taking naps $(P<$ $0.01)$, and feeling rested after a night's sleep $(P<0.01)$. The total questionnaire scores were not statistically significant $(P=0.78)$.

\section{Discussion}

Our study has demonstrated the presence of sleep problems in a significant proportion of elementary and middle school children in a predominantly Hispanic population in South Texas; there are several important differences in the selfreported sleep habits between these two groups. Elementary students reported both trouble sleeping and liking sleeping more often than middle school students. Notable differences between the two groups included bedtime resistance, sleep 
TABLE 3: Responses to the Children's Sleep Habits Questionnaire from middle school students.

\begin{tabular}{|c|c|c|c|c|}
\hline Qn \# & & Yes & No & \\
\hline 2 & Trouble sleeping & $28.77 \%$ & $71.23 \%$ & \\
\hline \multirow[t]{2}{*}{3} & Likes to sleep & $50.00 \%$ & $50.00 \%$ & \\
\hline & & Rarely & Sometimes & Usually \\
\hline \multicolumn{5}{|c|}{ Block 1: bedtime resistance } \\
\hline 4 & Goes to bed at same time & $11.21 \%$ & $30.06 \%$ & $58.73 \%$ \\
\hline 5 & Falls asleep in same bed & $26.49 \%$ & $20.73 \%$ & $52.78 \%$ \\
\hline 6 & Sleeps alone & $50.99 \%$ & $23.61 \%$ & $25.40 \%$ \\
\hline 7 & Falls asleep in other's bed & $48.81 \%$ & $30.56 \%$ & $20.63 \%$ \\
\hline 9 & Fights with parents to go to bed & $50.79 \%$ & $27.08 \%$ & $22.12 \%$ \\
\hline 10 & Hard to go to bed & $39.48 \%$ & $31.65 \%$ & $28.87 \%$ \\
\hline 11 & Ready to sleep at usual bedtime & $50.89 \%$ & $23.21 \%$ & $25.89 \%$ \\
\hline 15 & Stay up late when parents think you are asleep & $47.92 \%$ & $33.13 \%$ & $18.95 \%$ \\
\hline \multicolumn{5}{|c|}{ Block 2: sleep onset delay } \\
\hline 8 & Falls asleep in 20 minutes & $47.67 \%$ & $30.09 \%$ & $22.24 \%$ \\
\hline \multicolumn{5}{|c|}{ Block 3: sleep anxiety } \\
\hline 12 & Takes a special thing to bed & $58.33 \%$ & $20.63 \%$ & $21.03 \%$ \\
\hline 13 & Afraid of dark & $58.13 \%$ & $28.57 \%$ & $13.29 \%$ \\
\hline 14 & Afraid of sleeping alone & $43.15 \%$ & $33.93 \%$ & $22.92 \%$ \\
\hline \multicolumn{5}{|c|}{ Block 4: sleep duration } \\
\hline 16 & Sleeps too little & $45.46 \%$ & $37.49 \%$ & $17.05 \%$ \\
\hline 17 & Sleeps too much & $44.47 \%$ & $39.98 \%$ & $15.55 \%$ \\
\hline \multicolumn{5}{|c|}{ Block 5: night awakening } \\
\hline 18 & Wakes up at night when parents think you are asleep & $41.27 \%$ & $36.01 \%$ & $22.72 \%$ \\
\hline 19 & Trouble falling back asleep after waking up & $52.98 \%$ & $30.06 \%$ & $16.96 \%$ \\
\hline 20 & Have nightmares & $61.71 \%$ & $23.91 \%$ & $14.38 \%$ \\
\hline 21 & Wakes up due to pain & $61.90 \%$ & $22.22 \%$ & $15.87 \%$ \\
\hline 22 & Goes to other's bed during night & $43.55 \%$ & $27.78 \%$ & $28.67 \%$ \\
\hline \multicolumn{5}{|c|}{ Block 6: daytime sleepiness } \\
\hline 23 & Trouble waking up in morning & $41.35 \%$ & $31.81 \%$ & $26.84 \%$ \\
\hline 24 & Feels sleepy during day & $47.71 \%$ & $28.83 \%$ & $23.46 \%$ \\
\hline 25 & Takes naps during day & $29.92 \%$ & $29.42 \%$ & $40.66 \%$ \\
\hline 26 & Feels rested after a night's sleep & $23.96 \%$ & $36.78 \%$ & $39.26 \%$ \\
\hline
\end{tabular}

Qn \#: question number.

onset delay, and daytime sleepiness. The total questionnaire scores were similar in both groups of students, underscoring the importance of individual and grouped question responses in addition to the composite score.

Assessing adequacy of sleep hygiene in these populations was a major aim of this study. Middle school students appeared to adhere to traditional measures of sleep hygiene, such as consistent bedtime and location, compared to the elementary students; however, they reported more disobedient behaviors, such as fighting with their parents over going to bed. Elementary students more often stayed up after their parents thought they were asleep, though they were more likely to report falling asleep within 20 minutes. Our students were less likely to fall asleep within 20 minutes than those surveyed by a National Sleep Foundation (NSF) poll in 2004, in which $22 \%$ responded that they take more than 20 minutes to fall asleep [21]. Electronics and other toys in the bedroom can be used to discretely violate household rules; small screens (e.g., smartphones) and televisions in the bedroom have recently been associated with shorter sleep duration in a survey of 4 th through 7 th graders [22]. Both of our groups felt that they got an inappropriate amount (too much or too little) of sleep at most once a week. The sleep resistance answers obtained here were similar to another selfreported survey that recognized bedtime resistance in $27 \%$ of elementary school students [2]; this was by far the most common sleep problem identified in that group. The 2004 NSF poll reported that $42 \%$ children stall in going to bed [21].

Sleep anxiety has complicated interactions with sleep and may contribute to some of the sleep difficulties, potentially 
TABLE 4: Comparisons of sleep habits between elementary and middle school students.

\begin{tabular}{|c|c|c|c|}
\hline Qn \# & Item description & $P$ value ( $t$-test) & $P$ value $\left(\chi^{2}\right)$ \\
\hline 2 & Trouble sleeping & & $0.00^{*}$ \\
\hline 3 & Likes to sleep & & $0.00^{*}$ \\
\hline Block 1: bedtime resistance & & $0.01^{*}$ & \\
\hline 4 & Do you go to bed at same time every night on school nights? & & $0.00^{*}$ \\
\hline 5 & Do you fall asleep in same bed every night? & & $0.00^{*}$ \\
\hline 6 & Do you fall asleep alone? & & $0.00^{*}$ \\
\hline 7 & Do you falls asleep in parents', brother's, or sister's bed? & & 0.57 \\
\hline 9 & Do you fight with your parents about going to bed? & & $0.00^{*}$ \\
\hline 10 & Is it hard for you to go to bed? & & 0.35 \\
\hline 11 & Are you ready for bed at your usual bedtime? & & $0.01^{*}$ \\
\hline 15 & Do you stay up late when parents think you are asleep? & & $0.00^{*}$ \\
\hline \multicolumn{4}{|l|}{ Block 2: sleep onset delay } \\
\hline 8 & Do you fall asleep in about 20 minutes? & & $0.00^{*}$ \\
\hline Block 3: sleep anxiety & & 0.82 & \\
\hline 12 & Do you have a special thing you bring to bed? & & $0.00^{*}$ \\
\hline 13 & Are you afraid of the dark? & & $0.00^{*}$ \\
\hline 14 & Are you afraid of sleeping alone? & & $0.00^{*}$ \\
\hline Block 4: sleep duration & & 0.15 & \\
\hline 16 & Do you think you sleep too little? & & $0.00^{*}$ \\
\hline 17 & Do you think you sleep too much? & & $0.00^{*}$ \\
\hline Block 5: night awakening & & 0.66 & \\
\hline 18 & Do you wake up at night when parents think you are asleep? & & 0.05 \\
\hline 19 & Do you have trouble falling back to sleep if you wake up during the night? & & $0.00^{*}$ \\
\hline 20 & Do you have nightmares? & & $0.00^{*}$ \\
\hline 21 & Does pain wake you up at night? Where is that pain? & & 0.11 \\
\hline 22 & Do you sometimes go to someone's bed during the night? If yes who? & & $0.00^{*}$ \\
\hline Block 6: daytime sleepiness & & $0.00^{*}$ & \\
\hline 23 & Do you have trouble waking up in the morning? & & 0.27 \\
\hline 24 & Do you feel sleepy during the day? & & $0.00^{*}$ \\
\hline 25 & Do you take naps during the day? & & $0.00^{*}$ \\
\hline 26 & Do you feel rested after a night's sleep? & & $0.00^{*}$ \\
\hline Questions 2 to 26 (overall score) & & 0.78 & \\
\hline
\end{tabular}

${ }^{*} P<0.05$.

Qn \#: question number; $\chi^{2}$ : chi square.

explaining aberrations in sleep hygiene. Middle school students were significantly more likely to report fear of sleeping alone; they also more often sleep with someone else and go to someone else's bed during the night. Conversely, elementary students were more afraid of the dark and had nightmares and trouble falling back to sleep after awakening. This study was not designed to elucidate the reasons behind these fears, or whether the fears motivated the behaviors that were associated.

Causes of daytime sleepiness are multifactorial and may include intrinsic sleep disorders such as sleep-disordered breathing or narcolepsy, insufficient sleep syndrome, medical comorbidities, or medications. Self-identification of daytime sleepiness can be unreliable in children and adults. Questionnaires have been developed for this purpose, often asking the subject about falling asleep or dozing off in certain situations; some of these questionnaires include the Epworth Sleepiness Scale $[23,24]$ and the Children's Report of Sleep PatternsSleepiness Scale [25]. Another example is seen in this study: more than $40 \%$ of middle school students reported taking naps during the day 5-7 times per week, while only $23 \%$ reported feeling sleepy during the day on a usual basis. The proportion of these children that reported taking naps was unexpected, given that all are $>5$ years of age. However, these results are similar to an earlier study that showed that $32 \%$ of a group of 9-11-year-old children took daytime naps [26]. In that study, nappers did not report differences in nighttime sleep (though actigraphy showed shorted nighttime sleep) or more daytime sleepiness than nonnappers. Almost 30\% of all students surveyed reported difficulty waking up 5-7 days per 
week (similar in both groups). The previously mentioned NSF poll found that $29 \%$ of children under age 10 had difficulty waking up at least a few mornings per week [21]; the selfreport survey done by Blader and associates showed that $17 \%$ had morning wake up problems [2].

The CSHQ was initially designed to be completed by a parent or caregiver; we used a modified version designed to be answered directly by the child. We felt it was important to obtain the answers from the children directly for a number of reasons. First, children may become more independent and/or learn to hide certain "wrong" behaviors from their parents with age [11]; thus, parent-reported answers might introduce bias into some of the comparisons of interest. Both sets of respondents may be susceptible to social desirability bias, albeit from different sources. A parent may skew the answers to reflect "proper" sleep habits that have been disbursed by the media, peers, or their parents over many years. A child may similarly skew his or her answers, though the information is more limited, and the rules of the house can be presumed to play a larger role in the sense of right and wrong; thus, while the answers would still deviate from the true sleep habits, they would reflect a point of emphasis in the household. Previous studies have validated self-reported sleep habits from similar aged children $[25,27,28]$ and in adolescents [13]. Children self-report identified more sleep problems than parent report in a comparative study [20], though parent-reported mean scores on the parent-answered CSHQ from a community sample (56.2) [17] was higher than the mean scores for the student-answered surveys (44 in both groups) in the present study. No standardized assessment measures exist for testing sleep knowledge in children. Because of this, investigators construct and develop their own questionnaires for use in research settings; this limits clinical application. Blunden and associates have highlighted the need for such standard sleep knowledge measures [29]. The questionnaire we used in this study attempts to address the problem of insufficient sleep in children but does not directly quantify the amount of sleep achieved (or attempted). The questions ask the child to answer whether they think they get too much or too little sleep. Properly answering this question would require baseline knowledge of the appropriate amount of sleep for their age, which was also not assessed in this study.

An important consideration of our study includes the demographic breakdown of our study sample. The schools participating in this survey were predominantly Hispanic, reflecting the make-up of the community at large. Ethnicity and gender are known to have significant effects on sleep behaviors. Non-Caucasian children reported later bedtimes and had shorter sleep duration than Caucasian children [3033]. Previous studies have reported that boys had shorter sleep duration than girls on nonschool nights $[30,32-$ 34]. An actigraphic study found that girls and nonminority adolescents achieved more sleep [35] than others. Another study conducted on minority children found that girls aged 11-12 years slept 0.3 hours less than boys per day [36]. A much higher percentage of Hispanic children (74\%) have televisions in their bedroom, compared with white children (22\%) [37], which has a detrimental association with sleep duration [22].
As noted previously, much of the prior research on pediatric sleep habits has been done on primarily Caucasian populations; this difference may explain some of the discrepancies noted between our results and prior reports, including the NSF poll [20]. Ethnic and/or gender factors may affect how the answers from a parent and child might differ with respect to the child's sleep, as in this report. Collection of gender, age, and ethnicity data for the individual students was not possible within the constructs of this study. Therefore, any conclusions regarding the impact of each of these factors would be speculative. Participation in this questionnaire was done in large groups and classes; thus, it is felt that the participating student population is representative of the overall population of each school. These results cannot be assumed to pertain to populations other than the group described here. Replication of these results in other ethnic and socioeconomic groups may allow these findings to confidently be applied to a broader population.

Similarly, the lack of individual age data is a significant limitation. Texas state law requires that children between the ages of 6 and 18 years attend school; those 6 years of age on September 1 of that year are enrolled in first grade and they progress 1 grade level each September, provided acceptable academic and social progress. While children in a given school grade level are typically of a similar age, this assumption does not account for children that have been held back or "skipped" a grade for any reason or transferred from another education system with different requirements. Importantly, sleep habits are not the product of age alone; social interactions (friends, family) play a central role in behaviors, including sleep habits. While these results should not be applied to children of specific ages due to these limitations, they may be viewed in the context of social maturation and academic progression through school.

Because of the large number of questions in the questionnaire, multiple comparisons were performed, which introduces concern for Type 1 error. Because of the large number of data sets used and because of the high proportion of questions with significant differences (20/25 individual questions), the risk of such an error meaningfully altering the results is very low, so additional statistical adjustments were not performed.

Interventions for children and adolescents have been developed to address many of the sleep problems identified here through educations programs. The Australian Centre for Education in Sleep (ACES) conducted sleep education programs in Australia and New Zealand, using a PowerPoint lecture to increase sleep knowledge and improve sleep behaviors in adolescents. Significant improvements on sleep knowledge were shown in the Australian trials, and the New Zealand trial showed significant improvements in week and weekend sleep duration [38]. Positive feedback regarding the program was received from both teachers and students involved in these trials. Another unrelated sleep education study was performed in Australia [39]. This intervention consisted of four 50-minute classes over 4 weeks; while sleep knowledge improved, the target sleep variables did not. Our data show that disrupted sleep appears to begin younger than adolescence, so earlier intervention may be warranted. The current survey was part of a larger educational program, 
known as Keep Nurture and Inspire Good Habits in Teen Sleep (KNIGHTS), which utilizes a 3D animated sleep education movie to promote healthy sleep habits in elementary and middle school students [40].

\section{Conclusion}

Sleep abnormalities are present by the time children are in 4 th and 5th grades, with changes as they progress into middle school. Middle school students reported more adherence to traditional measures of sleep hygiene than the elementary students; however, they reported more disobedient behaviors. Bedtime resistance, sleep onset delay, and nighttime awakenings are more common among elementary school students, though middle school students are more likely to argue with their parents about going to bed. These differences may be attributed to a number of factors, including neurobiological development, evolving social awareness and interactions, and intrusion of generalized behavioral changes into sleep. Selfreported daytime sleepiness is more prevalent among middle school students. Educational efforts may be useful in guiding proper sleep habits if started at a younger age; this warrants further study. Further studies are suggested to look at specific age group and gender to help identify these issues even better.

\section{Disclosure}

This material was presented in part at the American College of Chest Physicians Annual Meeting, October 2014, Austin, TX.

\section{Conflict of Interests}

None of the authors have any conflict of interests to disclose.

\section{Acknowledgment}

The authors thank all the schoolteachers and counselors for their support.

\section{References}

[1] American Academy of Orthopaedic Surgeons, International Classification of Sleep Disorders, American Academy of Sleep Medicine, Darien, Ill, USA, 3rd edition, 2014.

[2] J. C. Blader, H. S. Koplewicz, H. Abikoff, and C. Foley, "Sleep problems of elementary school children: a community survey," Archives of Pediatrics \& Adolescent Medicine, vol. 151, no. 5, pp. 473-480, 1997.

[3] G. M. Nixon, J. M. D. Thompson, D. Y. Han et al., "Short sleep duration in middle childhood: risk factors and consequences," Sleep, vol. 31, no. 1, pp. 71-78, 2008.

[4] E. P. Ng, D. K. Ng, and C. H. Chan, "Sleep duration, wake/sleep symptoms, and academic performance in Hong Kong Secondary School Children," Sleep and Breathing, vol. 13, no. 4, pp. 357-367, 2009.

[5] H. Noland, J. H. Price, J. Dake, and S. K. Telljohann, "Adolescents' sleep behaviors and perceptions of sleep," Journal of School Health, vol. 79, no. 5, pp. 224-230, 2009.
[6] L. R. McKnight-Eily, D. K. Eaton, R. Lowry, J. B. Croft, L. Presley-Cantrell, and G. S. Perry, "Relationships between hours of sleep and health-risk behaviors in US adolescent students," Preventive Medicine, vol. 53, no. 4-5, pp. 271-273, 2011.

[7] K. M. Keyes, J. Maslowsky, A. Hamilton, and J. Schulenberg, "The great sleep recession: changes in sleep duration among US Adolescents, 1991-2012," Pediatrics, vol. 135, no. 3, pp. 460-468, 2015.

[8] M. E. Jewett, J. K. Wyatt, A. R.-D. Cecco, S. Bir Khalsa, D.-J. Dijk, and C. A. Czeisler, "Time course of sleep inertia dissipation in human performance and alertness," Journal of Sleep Research, vol. 8, no. 1, pp. 1-8, 1999.

[9] M. W. Johns, "A new method for measuring daytime sleepiness: the Epworth sleepiness scale," Sleep, vol. 14, no. 6, pp. 540-545, 1991.

[10] M. A. Carskadon, A. R. Wolfson, C. Acebo, O. Tzischinsky, and R. Seifer, "Adolescent sleep patterns, circadian timing, and sleepiness at a transition to early school days," Sleep, vol. 21, no. 8, pp. 871-881, 1998.

[11] M. A. Carskadon, J. Mindell, and C. Drake, "Contemporary sleep patterns of adolescents in the USA: results of the 2006 National Sleep Foundation Sleep in America poll," Journal of Sleep Research, vol. 15, p. 42, 2006.

[12] Y. Iwadare, Y. Kamei, A. Oiji et al., "Study of the sleep patterns, sleep habits, and sleep problems in Japanese elementary school children using the CSHQ-J," The Kitasato Medical Journal, vol. 43, pp. 31-37, 2013.

[13] A. R. Wolfson, M. A. Carskadon, C. Acebo et al., "Evidence for the validity of a sleep habits survey for adolescents," Sleep, vol. 26, no. 2, pp. 213-216, 2003.

[14] S. J. Crowley, C. Acebo, G. Fallone, and M. A. Carskadon, "Estimating dim light melatonin onset (DLMO) phase in adolescents using summer or school-year sleep/wake schedules," Sleep, vol. 29, no. 12, pp. 1632-1641, 2006.

[15] J. S. Loredo, X. Soler, W. Bardwell, S. Ancoli-Israel, J. E. Dimsdale, and L. A. Palinkas, "Sleep health in U.S. Hispanic population,” Sleep, vol. 33, no. 7, pp. 962-967, 2010.

[16] Demographic analysis and student projections for the Corpus Christi Independent School District, 2013, http://echalkweb .ccisd.us/www/CorpusChristi/site/hosting/Board\%20Meetings/ 2013\%20Agendas/03-25-13\%20Regular\%20Agenda\%20(approved \%20by\%20PF).pdf.

[17] J. A. Owens, A. Spirito, and M. McGuinn, “The Children's Sleep Habits Questionnaire (CSHQ): psychometric properties of a survey instrument for school-aged children," Sleep, vol. 23, no. 8, pp. 1043-1051, 2000.

[18] J. E. Lehto and L. Uusitalo-Malmivaara, "Sleep-related factors: associations with poor attention and depressive symptoms," Child: Care, Health and Development, vol. 40, no. 3, pp. 419-425, 2014.

[19] J. A. Owens, A. Spirito, M. McGuinn, and C. Nobile, "Sleep habits and sleep disturbance in elementary school-aged children," Journal of Developmental and Behavioral Pediatrics, vol. 21, no. 1, pp. 27-36, 2000.

[20] J. A. Owens, A. Spirito, M. McGuinn, and C. Nobile, "Sleep habits and sleep disturbance in elementary school-aged children," Journal of Developmental \& Behavioral Pediatrics, vol. 21, no. 1, pp. 27-36, 2000.

[21] J. A. Mindell, L. J. Meltzer, M. A. Carskadon, and R. D. Chervin, "Developmental aspects of sleep hygiene: findings from the 2004 National Sleep Foundation Sleep in America Poll," Sleep Medicine, vol. 10, no. 7, pp. 771-779, 2009. 
[22] J. Falbe, K. K. Davison, R. L. Franckle et al., "Sleep duration, restfulness, and screens in the sleep environment," Pediatrics, vol. 135, no. 2, pp. e367-e375, 2015.

[23] M. W. Johns, "A new method for measuring daytime sleepiness: the epworth sleepiness scale," Sleep, vol. 14, no. 6, pp. 540-545, 1991.

[24] C. S. Melendres, J. M. Lutz, E. D. Rubin, and C. L. Marcus, "Daytime sleepiness and hyperactivity in children with suspected sleep-disordered breathing," Pediatrics, vol. 114, no. 3, pp. 768775, 2004.

[25] L. J. Meltzer, S. Biggs, A. Reynolds, K. T. Avis, V. M. Crabtree, and K. B. Bevans, "The Children's Report of Sleep PatternsSleepiness Scale: a self-report measure for school-aged children," Sleep Medicine, vol. 13, no. 4, pp. 385-389, 2012.

[26] G. M. Kieckhefer, T. M. Ward, S.-Y. Tsai, and M. J. Lentz, "Nighttime sleep and daytime nap patterns in school age children with and without asthma," Journal of Developmental and Behavioral Pediatrics, vol. 29, no. 5, pp. 338-344, 2008.

[27] L. J. Meltzer, K. T. Avis, S. Biggs et al., "The children's report of sleep patterns (CRSP): a self-report measure of sleep for schoolaged children," Journal of Clinical Sleep Medicine, vol. 9, no. 3, pp. 235-245, 2013.

[28] M. Yamakita, M. Sato, D. Ando, K. Suzuki, and Z. Yamagata, "Availability of a simple self-report sleep questionnaire for 9- to 12-year-old children," Sleep and Biological Rhythms, vol. 12, no. 4, pp. 279-288, 2014.

[29] S. L. Blunden, J. Chapman, and G. A. Rigney, "Are sleep education programs successful? The case for improved and consistent research efforts," Sleep Medicine Reviews, vol. 16, no. 4, pp. 355370, 2012.

[30] M. C. Gulliford, C. E. Price, R. J. Rona, and S. Chinn, "Sleep habits and height at ages 5 to 11," Archives of Disease in Childhood, vol. 65, no. 1, pp. 119-122, 1990.

[31] J. C. Spilsbury, A. Storfer-Isser, D. Drotar et al., "Sleep behavior in an urban US sample of school-aged children," Archives of Pediatrics \& Adolescent Medicine, vol. 158, no. 10, pp. 988-994, 2004.

[32] X. Liu, L. Liu, J. A. Owen, and D. L. Kaplan, "Sleep patterns and sleep problems among schoolchildren in the United States and China," Pediatrics, vol. 115, no. 1, pp. 241-249, 2005.

[33] S. N. Biggs, K. Lushington, A. James Martin, C. van den Heuvel, and J. Declan Kennedy, "Gender, socioeconomic, and ethnic differences in sleep patterns in school-aged children," Sleep Medicine, vol. 14, no. 12, pp. 1304-1309, 2013.

[34] D. K. Ng, K.-L. Kwok, J. M. Cheung et al., "Prevalence of sleep problems in Hong Kong primary school children: a community-based telephone survey," Chest, vol. 128, no. 3, pp. 13151323, 2005.

[35] M. Moore, H. L. Kirchner, D. Drotar, N. Johnson, C. Rosen, and S. Redline, "Correlates of adolescent sleep time and variability in sleep time: the role of individual and health related characteristics," Sleep Medicine, vol. 12, no. 3, pp. 239-245, 2011.

[36] W. W. Wong, C. L. Ortiz, D. Lathan et al., "Sleep duration of underserved minority children in a cross-sectional study," BMC Public Health, vol. 13, no. 1, article 648, 2013.

[37] E. M. Taveras, K. H. Hohman, S. Price, S. L. Gortmaker, and K. Sonneville, "Televisions in the bedrooms of racial/ethnic minority children: how did they get there and how do we get them out?" Clinical Pediatrics, vol. 48, no. 7, pp. 715-719, 2009.
[38] S. Blunden, G. Kira, M. Hull, and R. Maddison, "Does sleep education change sleep parameters? Comparing sleep education trials for middle school students in Australia and New Zealand," The Open Sleep Journal, vol. 5, pp. 12-18, 2012.

[39] L. Moseley and M. Gradisar, "Evaluation of a school-based intervention for adolescent sleep problems," Sleep, vol. 32, no. 3, pp. 334-341, 2009.

[40] S. Surani, S. Rao, A. Khimani et al., "Effect of animated movie in combating child sleep health problems," Chest, vol. 145, p. 446A, 2014. 


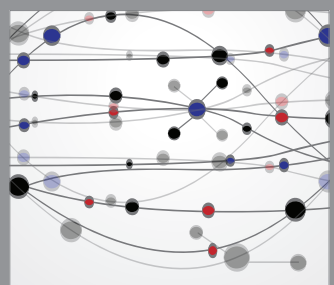

The Scientific World Journal
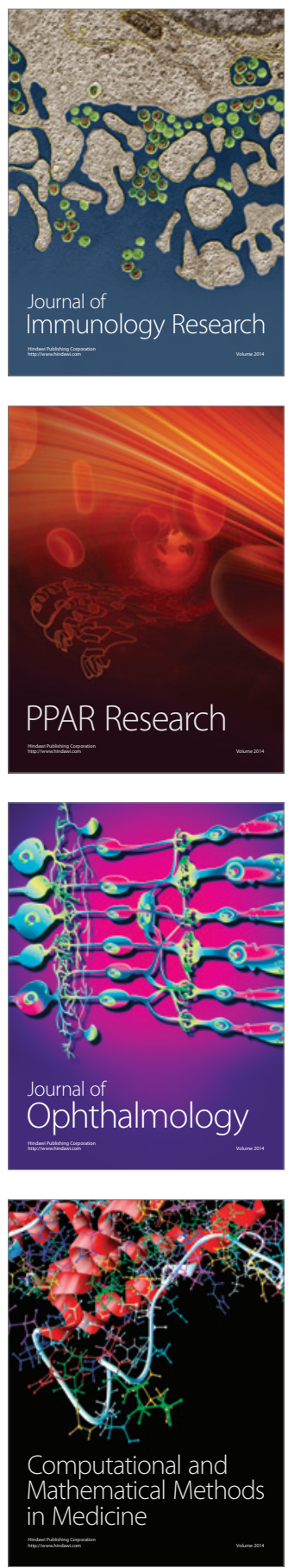

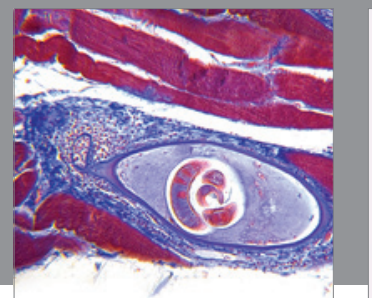

Gastroenterology

Research and Practice
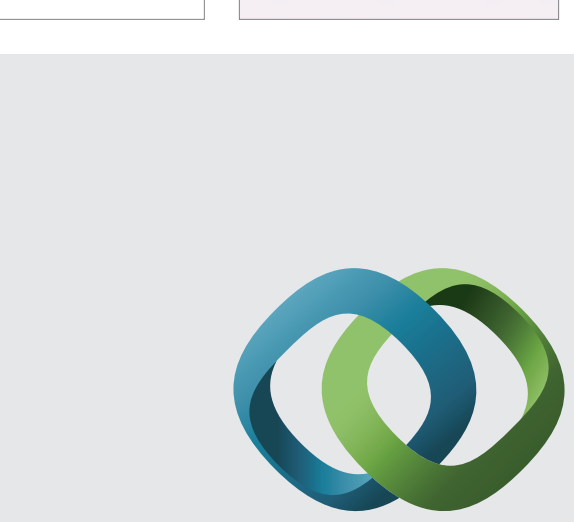

\section{Hindawi}

Submit your manuscripts at

http://www.hindawi.com
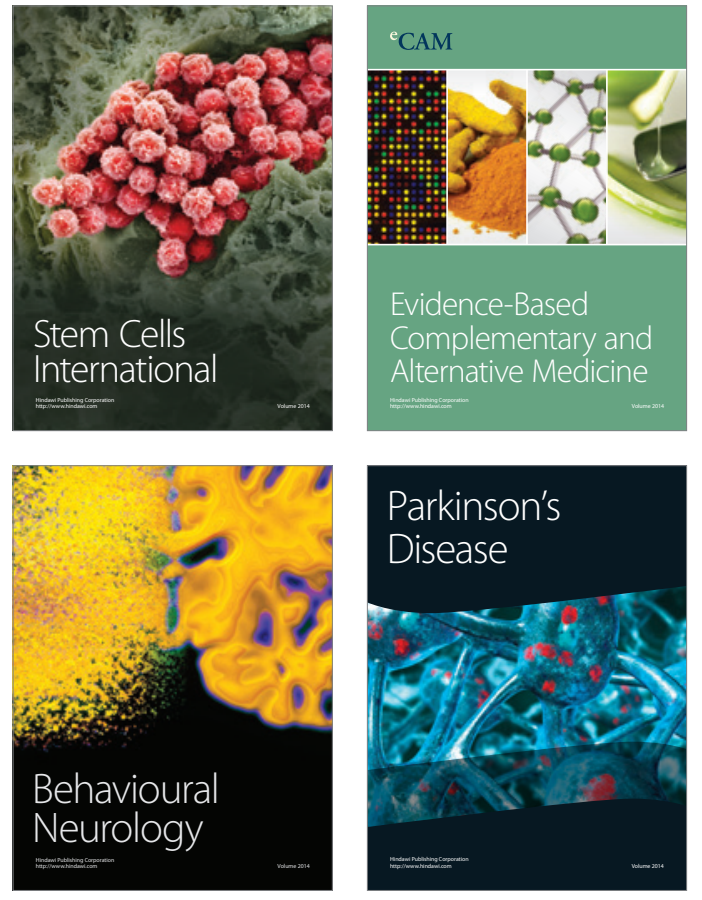
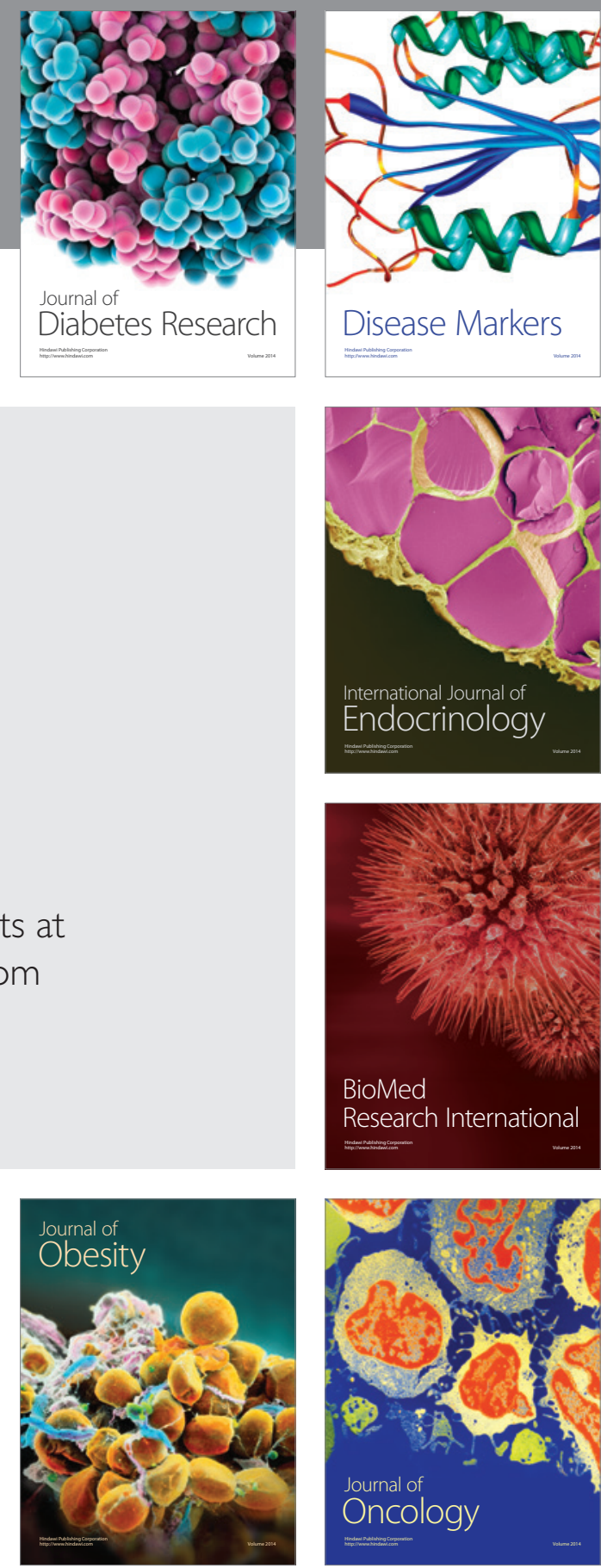

Disease Markers
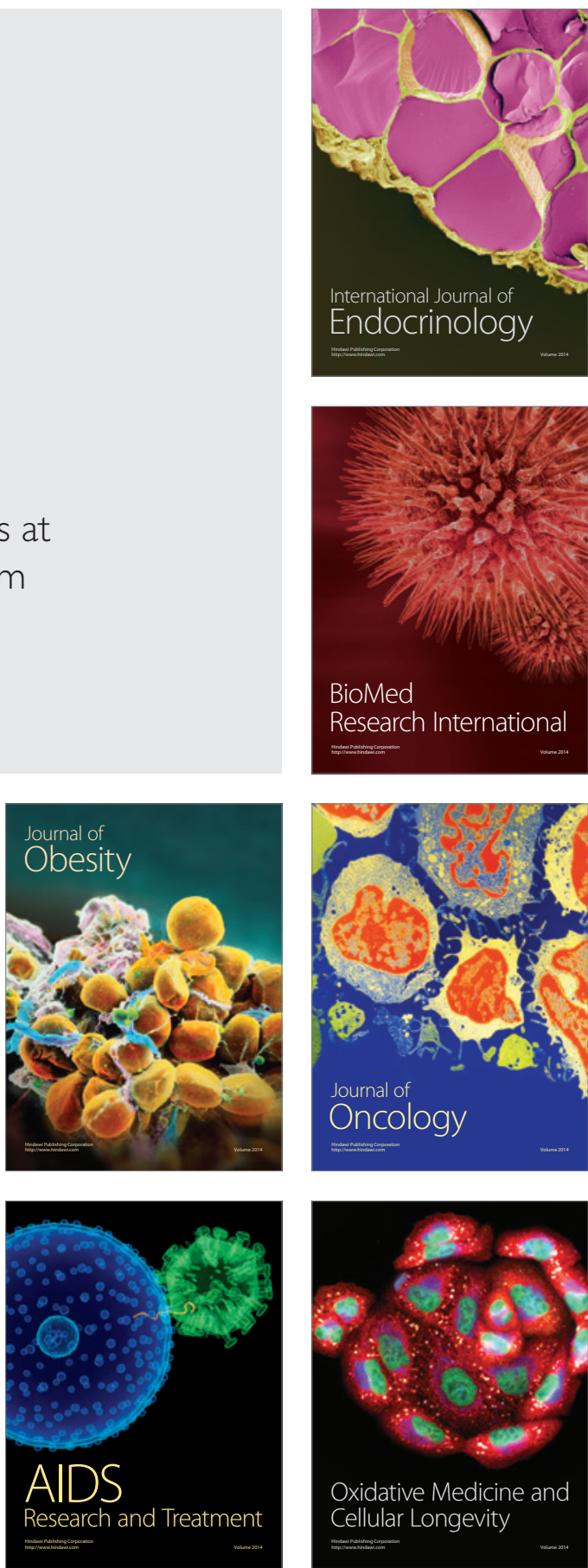